\title{
Delayed hemobilia due to hepatic artery pseudo-aneurysm: a pitfall of laparoscopic cholecystectomy
}

\author{
Mawaddah Alrajraji ${ }^{1}$, Abrar Nawawi ${ }^{1}$, Reda Jamjoom ${ }^{1}$, Yousef Qari $^{2}$ and Murad Aljiffry ${ }^{1 *}$
}

\begin{abstract} rare, potentially life threatening condition. the aneurysm and hepaticojujenostomy.

\section{Background}

Hemobilia and vascular injuries are among the most important - albeit not necessarily the most common- complications of laparoscopic cholecystectomies (LC), due to the high morbidity and mortality associated with the condition [1-3]. The symptoms of hemobilia commonly appear within the early postoperative period or as late as 4 weeks [3]. Alongside with a detailed literature review, we report a case presenting 8 months after LC with right hepatic artery pseudo aneurysm in association with a complex injury to the common bile duct. To our knowledge there are two similar cases in the literature reporting a delayed hepatic artery pseudoanyrusm presenting up to a year following LC $[4,5]$ (Table 1$)$.
\end{abstract}

Background: Hepatic artery pseudoaneurysm as a complication of laparoscopic cholecystectomy is considered a

Case presentation: We report a case of late onset hemobilia presenting 8 months following elective laparoscopic cholecystectomy with complex biliary and vascular injury. The patient was treated surgically with primary repair of

Conclusion: A high index of suspicion should be raised when encountering a patient with massive upper Gl bleeding and a previous history of hepatobiliary manipulation or surgery regardless of postoperative period.

\section{Case presentation}

A 41-year-old female patient presented to our emergency department with history of upper gastrointestinal (UGI) bleeding in the form of painless coffee ground vomitus and melena. Patient has no significant past medical history apart from uneventful elective laparoscopic cholecystectomy due to a remote episode of acute

* Correspondence: dr.aljiffry@gmail.com

${ }^{1}$ Department of Surgery, Faculty of Medicine, King Abdulaziz University, Jeddah, Saudi Arabia

Full list of author information is available at the end of the article cholecystitis in another institution 8 months prior to her presentation. Upon reviewing the patient's charts, the operation was smooth, no intraoperative complications encountered, monopolar cautery energy source was used and no intraoperative cholangiogram was obtained.

The patient had history of previous attack of minimal UGI bleeding 6 weeks post cholecystectomy, at that time an upper endoscopy and ERCP were done showing hemobilia, and a stent was placed in the common bile duct. Following that, the patient was relieved of symptoms and a CT study confirmed the presence of a small $(<0.25 \mathrm{~cm})$ right hepatic artery pseudoaneurysm. The patient was offered the option of embolization, however she refused the treatment and lost follow up until the current presentation.

Upon her presentation to our center, the patient was pale, tachycardiac (100-110 bpm) and normotensive. Abdomen was soft and lax with no sign of peritonitis were noted upon palpation.

\section{Laboratory results}

Hemoglobin: $10.3 \mathrm{~g} \backslash \mathrm{L}$, Hematocrit: 33, Platelets: $44 \times$ $10^{9} /$ L. Coagulation profile was normal and Liver function showed a mild elevation of the liver enzymes.

The patient was hospitalized and resuscitated, after which she was prepared for an emergency UGI endoscopy, where no bleeding source was identified in 
Table 1 Summary of similar cases (post laparoscopic cholecystectomy hepatic artery pseudoaneurysm) reported in the literature

\begin{tabular}{|c|c|c|c|c|c|c|c|}
\hline Author & Age & Gender & Presentation & diagnosis & $\begin{array}{l}\text { Time of } \\
\text { presentation }\end{array}$ & Procedure & Outcome \\
\hline Genyk YS [18] & 57 years & $\mathrm{F}$ & Pain, UGIB and jaundice. & HPA & 2 weeks & Embolization & 2 year follow up \\
\hline $\begin{array}{l}\text { Jean-Denis Yelle, } \\
\text { et al. [19] }\end{array}$ & 48 years & $\mathrm{F}$ & Pain, UGIB. & $\begin{array}{l}\text { Contrast study of the fistula, } \\
\text { ERCP\& HPA }\end{array}$ & NA & Open laparotomy & 6 month \\
\hline Siablis D, et al. [7] & 29 years & M & Pain, jaundice and UGIB. & HPA & NA & Embolization & Close follow ups \\
\hline $\begin{array}{l}\text { Sam T.M. Kwauk, } \\
\text { et al. [20] }\end{array}$ & 39 years & $\mathrm{F}$ & NIV, pain and jaundice. & $\mathrm{CT}$ and $\mathrm{HPA}$ & NA & Selective embolization & 4 month \\
\hline Ribeiro A, et al. [4] & 57 years & $\mathrm{F}$ & Pain & UGI endoscopy, CT and HPA & 13 months & Emergent laparotomy. & NA \\
\hline de Blaauw I, et al. [21] & 38 years & $\mathrm{F}$ & Pains and melena & NA & NA & Emergent laparotomy. & 7 month \\
\hline \multirow[t]{9}{*}{ T nicholoson et al. [22] } & 43 years & $\mathrm{F}$ & Hematemesis & NA & 43 days & Embolization & Well at 15 month \\
\hline & 69 years & M & & & 10 days & & Well at 5 years \\
\hline & 54 years & $\mathrm{F}$ & & & 5 days & & Well at 7 years \\
\hline & 42 years & $\mathrm{F}$ & & & 8 days & & Well at 4 years \\
\hline & 65 years & $\mathrm{F}$ & & & 18 days & & Well at 6 years \\
\hline & 47 years & $\mathrm{F}$ & & & 6 days & & Well at 3 years \\
\hline & 39 years & M & & & 7 days & & Well at 5 years \\
\hline & 68 years & $\mathrm{F}$ & & & 9 days & & Well at 2 years \\
\hline & 53 years & $\mathrm{F}$ & & & 12 days & & Well at 6 years \\
\hline Dogru O, et al. [23] & 62 years & $\mathrm{F}$ & UGIB & Ultrasound and UGI endoscopy & NA & Exploratory laparotomy & NA \\
\hline lannelli A et al., [24], & 36 years & $\mathrm{F}$ & Not mentioned & NA & NA & Selective embolization & NA \\
\hline $\begin{array}{l}\text { G Roche-Nagle, } \\
\text { et al. [25] }\end{array}$ & 58 years & $\mathrm{F}$ & Pain, and vitally collapsed & $\mathrm{CT} \& \mathrm{HPA}$ & NA & Exploratory laparotomy & Uneventful recovery. \\
\hline \multirow[t]{3}{*}{ Mandur Ma et al. [15], } & 57 years & M & UGIB & NA & 2 weeks & Embolization & Well at 22 month \\
\hline & 63 years & $\mathrm{F}$ & UGIB & NA & 4 weeks & Embolization & Well at 12 month \\
\hline & 54 years & M & UGIB & NA & 3 weeks & Ligation & Well at 6 months \\
\hline Nakase Y, et al. [26] & 63 years & $\mathrm{F}$ & Pain and UGIB & HPA & NA & Selective embolization & NA \\
\hline Masannat YA [27] & 71 years & & Not mentioned & Angiogram & NA & Coil embolization & NA \\
\hline Srinivasaiah N [28] & 57 years & M & Pain and hematemesis & Ultrasound, CT and HPA & 4 weeks & Radiological intervention & NA \\
\hline Yao CA, et al. [29] & 54 years & M & Pain, UGIB, and disturbed LFTs. & $C T$. & NA & $\begin{array}{l}\text { Angiography with } \\
\text { embolization }\end{array}$ & NA \\
\hline Sansonna et al., [30] & 44 years & $\mathrm{F}$ & UGIB & $C T$ & 3 weeks & $\begin{array}{l}\text { Angiography with } \\
\text { embolization }\end{array}$ & Well at 2 weeks \\
\hline Paseka T et al., [31] & 51 years & M & UGIB & $C T \& H P A$ & Months & Exploratory laparotomy & Well at 6 months. \\
\hline \multirow[t]{2}{*}{ AD Mate et al., [32] } & 45 years & M & LGIB & HPA & 15 days & Emergency laparotomy & NA \\
\hline & 50 years & M & Pain, jaundice and UGIB & UGl endoscopy \& HPA & 3 months & Emergent laparotomy. & 1 year \\
\hline
\end{tabular}


Table 1 Summary of similar cases (post laparoscopic cholecystectomy hepatic artery pseudoaneurysm) reported in the literature (Continued)

El Bouhaddouti,

et al. [33]

al. [34]

$C T, E R C P, \& H P A$.

4 weeks

Angiography and

well at discharge

Tun-Abraham ME

67 years $M$

CT.

NA

embolization.

Abdallah S et al., [36]

40 years $M$

abdominal bleeding

$C T \& H P A$.

No evidence of recurrent

mbolization

bleeding

Chih yang Hsiao

40 years $M$

Jaundice, pain and oozing blood from

$M R \& H P A$.

NA

Selective embolization

NA

et al., [37] drainage.

angiography.

NA

Abbreviation definition: NA not available, UGIB upper gastrpintestinal bleeding, HPA hepatic selective angiography, ERCP endoscopic retrograde cholangiography, $L C$ laparoscopic cholecystectomy 
the stomach or duodenum. However, blood was noticed flowing from the major duodenal papilla raising suspicion of hemobilia. On ERCP the old stent was dislodged and a stricture was identified at the common bile duct (CBD) extending into the hepatic duct but below the bifurcation. In addition, the bile duct was filled with clots and the right hepatic artery started to fill with contrast. A plastic stent was placed across the stricture (Fig. 1). CT abdominal angiography was done showed saccular lesion at the right hepatic artery suggestive of the presence of pseudoaneurysm $(1.5 \mathrm{~cm})$ (Figs. 2 and 3). Bleeding was initially controlled following the ERCP (stenting). Shortly after, the patient deteriorated again, with a drop of her hemoglobin to $7.7 \mathrm{~g} \backslash \mathrm{L}$, she was transferred to the critical care unit, resuscitated with 4 units of PRBCS and platelets. Patient was hemodynamically stable and referred for angiography for angio-embolization, which was not successful due to failure to cannulate the common hepatic artery. The patient continued to experience gastrointestinal bleeding requiring further transfusion of blood products. She was taken to the operating room for an emergency exploratory laparotomy.

\section{Operative note}

Exploration of the abdomen was obtained through a midline laparotomy; there was no evidence of heamoperitonium. After obtaining proximal control of the common hepatic artery, isolation of right hepatic artery was difficult. The area of the porta hepatis was thickened and edematous probably due to previous cholangitis and ERCPs. The CBD was divided to facilitate the exposure of the right hepatic artery. Following that, the right hepatic artery course was isolated and controlled proximal to the pseudo-aneurysm (Fig. 4). Upon dissection the aneurysm was accidently opened with minimal back bleeding. The wall of the pseudo aneurysm was refreshed and the right hepatic artery was closed in a primary repair fashion.

Roux-en-y hepatico-jujenostomy was performed. The stent has migrated and it was felt in the transverse colon, it was retrieved through a colotomy.

The patient had an uneventful recovery apart from wound infection. Her LFT gradually returned back to normal levels. After discharge the patient had been followed up for 14 months with no evidence of reoccurrence of bleeding.

\section{Discussion}

Laparoscopic cholecystectomy (LC) carries the risk of biliary and vascular iatrogenic injuries even in the hands of most experienced surgeons. Despite its many benefits in comparison to open procedure it carries a 10-fold increased risk of iatrogenic biliary and vascular injuries [3]. Laparoscopic biliary tree injuries are reported in $0.3-1 \%$ of procedures, whereas vascular injuries reported in $0.25-0.5 \%(7-9)$. It is well known in the literature that intraoperative bleeding is the most common manifestation of LC iatrogenic arterial injury followed by ligation. A less common manifestation of post LC iatrogenic arterial injury is presented here.

Approximately $10 \%$ of all the reported cases of hemobilia are secondary to iatrogenic hepatic artery pseudoaneurysms (Table 1) (8).

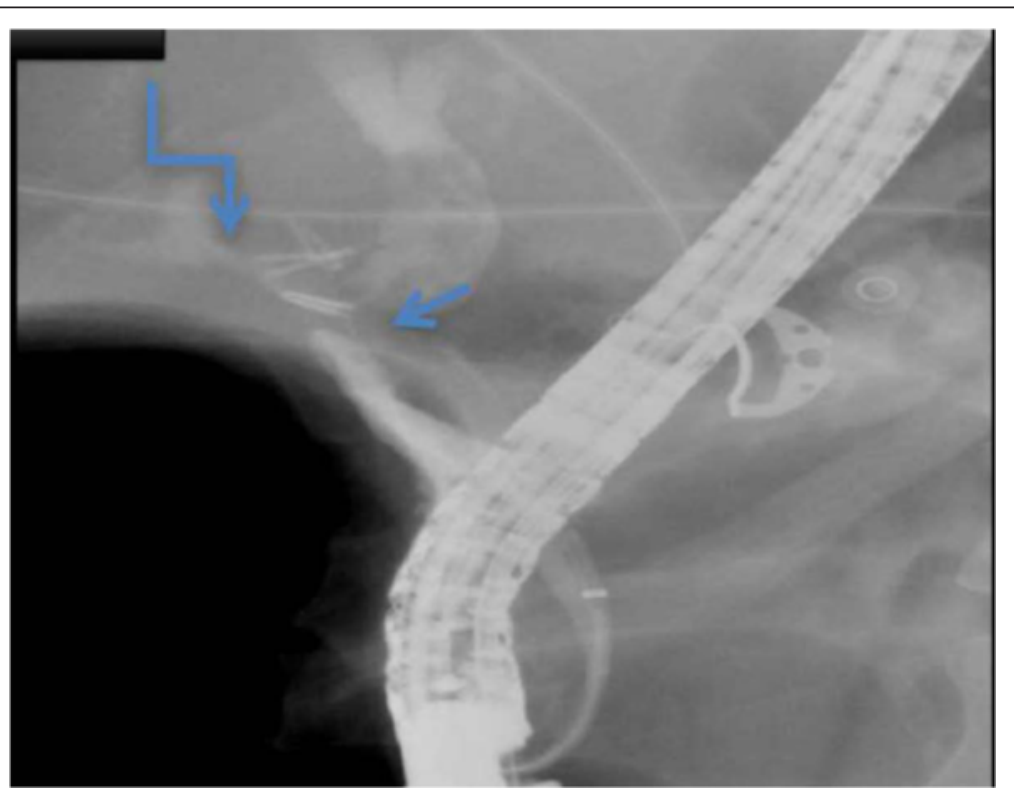

Fig. 1 ECRP study: showing the stricture of the CBD (straight arrow), with filling defect of the CHD and contrast filling the right hepatic artery communication between hepatic artery and CHD (angulated arrow) 


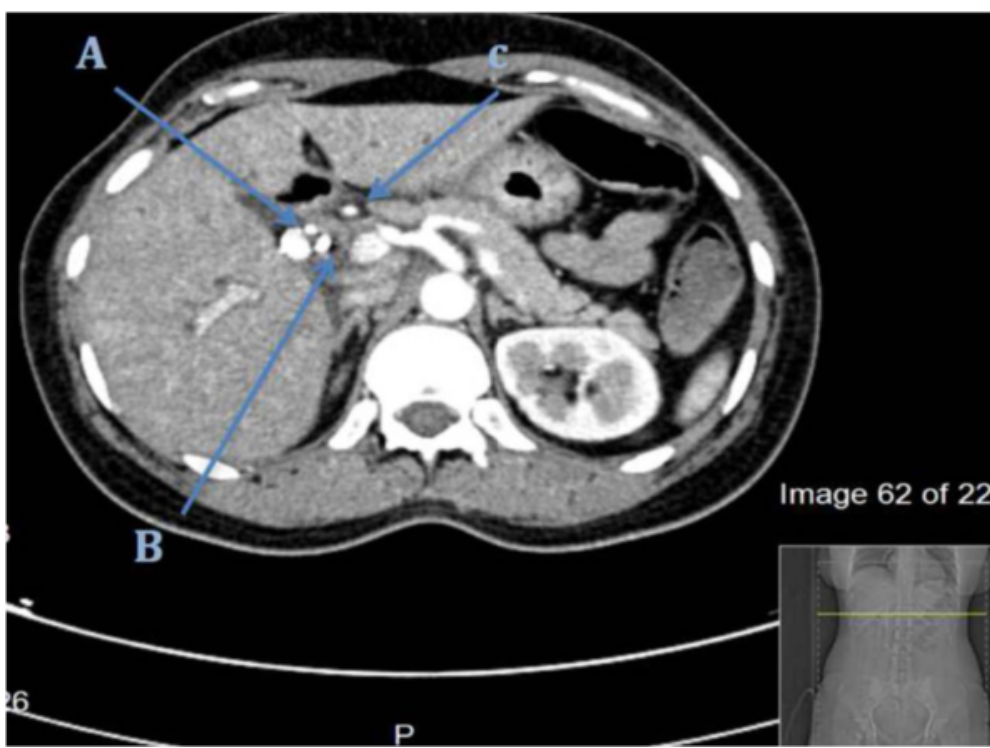

Fig. 2 CT study, an axial cut: the arrows points at, A: right hepatic artery psuedoaneurysm B: Stent C: common hepatic artery

Upper GI hemorrhage is the most common presentation of a ruptured right hepatic artery pseudo-aneurysm into the biliary tract. However, the classic presentation of hemobilia known as Quinke's triad is seen in less than $40 \%$ of patients [1, 6, 7].

To date, the definite pathological explanation of post LC hemobilia is still unclear but suggested mechanisms are mechanical, thermal injuries specially monopolar coagulation during laparoscopic surgeries and surgical clips encroachments [8-10]. Bile leak and superimposed infection are important precipitating factors, It has been reported that bile acid could contribute to the injury to the vascular wall resulting in delayed healing of the vessel wall which leads to the development of pseudoaneurysm [11]. We believe the mechanism of injury in our patient is thermal, due to the presence of vascular and biliary injuries and her delayed presentation.

There are several options for diagnosing and managing such condition, Upper gastrointestinal endoscopic evaluation is fundamental to exclude the more common causes of UGI bleeding [12]. In the current Literature nearly $12 \%$ of cases reported diagnosed endoscopically [13].

Contrast enhanced computed tomography of the abdomen aids in determining the diverse etiological causes of the hemobilia [14]. The difficulty in making the

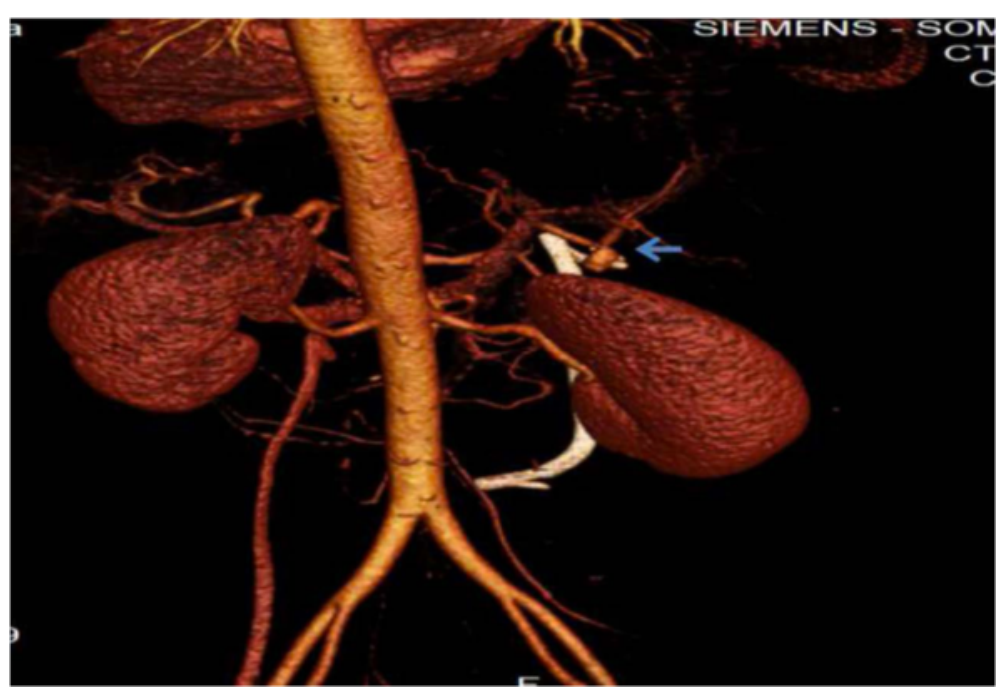

Fig. 3 3D angiogram demonstrating aneurysm of hepatic artery (straight arrow) 


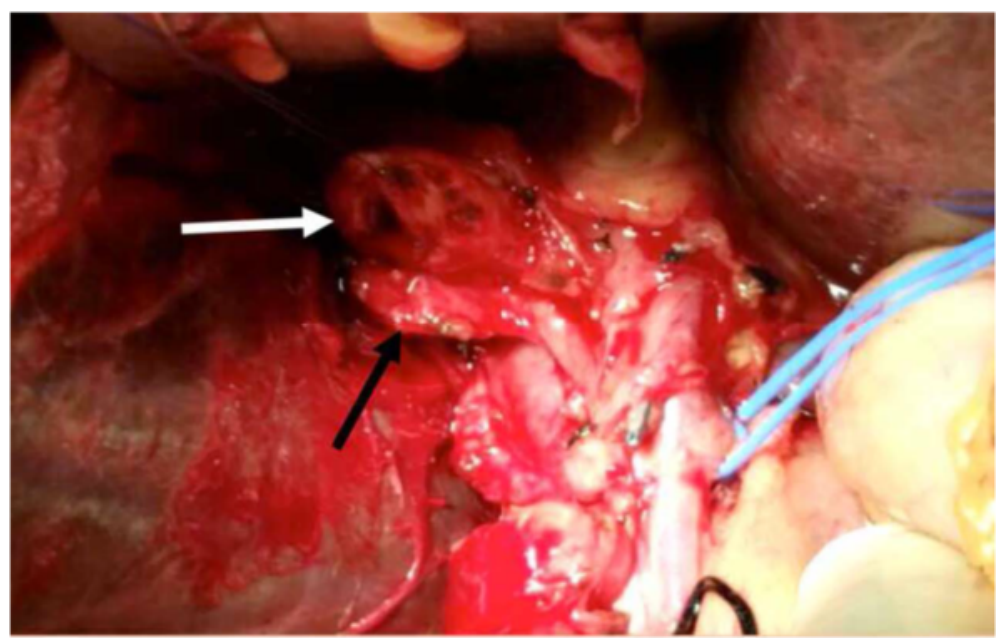

Fig. 4 Intra-operative: the arrows points at, A: (white) Common bile duct, B: (black) Right hepatic artery

diagnosis of hemobilia might be attributable to the fact that the bleeding is usually intermittent.

The management of hemobilia is an acute emergency as patient might exsanguinate when ruptured. The therapeutic aim is to stop the bleeding and to relive biliary obstruction [13]. Transarterial embolization (TAE) is the treatment choice for all causes of hepatic artery aneurysm with a high rate of success, surgical intervention should be done for selected patients who fail a trial of embolization (12) as in our case. Angiography offers the advantage of minimally invasive procedure, and it also represents an effective treatment choice for this potentially fatal complication $[15,16]$.

Surgery is narrowed to conditions requiring; bile duct repair, extra-hepatic lesion or gallbladder hemorrhage, and for failure of TAE $[15,17]$.

The time phase between confirming the diagnosis of hemobilia and the decision for surgical intervention in case of absence or failure of embolization is crucial and must be managed meticulously by the attending surgeon. As these patients are at risk of sudden rupture and exsanguination.

\section{Conclusion}

A high index of suspicion should be considered by all treating surgeons when encountering instances of hemobilia in patients presenting with upper GI hemorrhage with a past history of cholecystectomy regardless of the post-operative period. Assessment of the hepatic arteries is an important aspect of the investigation of all biliary injuries. Intraoperative preventive measures are paramount in preventing these complications, such as careful dissection and the avoidance of cautery usage adjacent to the vasculo-biliary structures during LC.

\section{Funding}

The authors declare that they have no financial interest to declare in relation to the content of this article.

Availability of data \& material

All data and material presented in the article are available upon request.

\section{Authors' contributions}

MA: literature review and summarized all previous similar cases, wrote part of introduction and discussion. AN: wrote the case details and clinical coarse, improved the introduction and photography. RJ: surgeon who performed vascular repair in the case, reviewed the whole manuscript, offered critiques and improved the discussion. YQ: reviewed the whole manuscript, offered critiques and improved the discussion. MA: surgeon who performed the operation, reviewed the case, wrote part of discussion and introduction. All authors read and approved the final manuscript.

\section{Competing interest}

The authors declare that they have no competing interests. All authors agree to the terms of the Biomed Central Copyright and License.

\section{Consent for publication}

Written informed consent was obtained from the patient for publication of this case report and any accompanying images. A copy of the written consent is available for review by the editor of this journal.

\section{Ethics approval and consent to participate}

This case report was approved by King Abdulaziz University Hospital ethical committee.

\section{Disclosure}

The authors declare no conflict of interest in the work to produce this article.

\section{Author details}

${ }^{1}$ Department of Surgery, Faculty of Medicine, King Abdulaziz University, Jeddah, Saudi Arabia. ${ }^{2}$ Department of Medicine, Faculty of Medicine, King Abdulaziz University, Jeddah, Saudi Arabia.

Received: 16 April 2016 Accepted: 10 August 2016

Published online: 22 August 2016

\section{References}

1. Sandblom P, Saegesser F, Mirkovitch V. Hepatic hemobilia: hemorrhage from the intrahepatic biliary tract, a review. World J Surg. 1984;8(1):41-50.

2. Ross FP. Hemobilia (Biliary Tract Hemorrhage): history, pathology, diagnosis and treatment. Arch Surg. 1973;106(2):245 
3. Connor S, Garden OJ. Bile duct injury in the era of laparoscopic cholecystectomy. Br J Surg. 2006;93(2):158-68.

4. Ribeiro A, et al. Hemobilia due to hepatic artery pseudoaneurysm thirteen months after laparoscopic cholecystectomy. J Clin Gastroenterol. 1998:26(1):50-3.

5. Milburn J, et al. Right hepatic artery pseudoaneurysm thirteen months following laparoscopic cholecystectomy. EJVES Extra. 2007:13(1):1-3.

6. Siablis $\mathrm{D}$, et al. Hemobilia secondary to hepatic artery pseudoaneurysm: an unusual complication of bile leakage in a patient with a history of a resected IIIb Klatskin tumor. World J Gastroenterol. 2005;11(33):5229-31.

7. Siablis $\mathrm{D}$, et al. Hepatic artery pseudoaneurysm following laparoscopic cholecystectomy: transcatheter intraarterial embolization. Hepatogastroenterology. 1996;43(11):1343-6.

8. Merrell SW, Schneider PD. Hemobilia-evolution of current diagnosis and treatment. West J Med. 1991;155(6):621-5.

9. Morino M. Randomized clinical trial of ultrasonic versus electrocautery dissection of the gallbladder in laparoscopic cholecystectomy ( $\mathrm{Br}$ J Surg 2003; 90: 799-803). Br J Surg. 2003;90(10):1306.

10. Curet $\mathrm{P}$, et al. Hepatic hemobilia of traumatic or iatrogenic origin: recent advances in diagnosis and therapy, review of the literature from 1976 to 1981. World J Surg. 1984;8(1):2-8

11. Hofmann AF. Bile acids: the good, the bad, and the ugly. News Physiol Sci. 1999;14:24-9.

12. Cattan $\mathrm{P}$, et al. Hemobilia caused by a pseudoaneurysm of the hepatic artery diagnosed by EUS. Gastrointest Endosc. 1999;49(2):252-5.

13. Napolitano V, et al. A severe case of hemobilia and biliary fistula following an open urgent cholecystectomy. World J Emerg Surg. 2009;4:37.

14. Rencuzogullari A, et al. Hemobilia as a result of right hepatic artery pseudoaneurysm rupture: an unusual complication of laparoscopic cholecystectomy. Int J Surg Case Rep. 2014;5(3):142-4.

15. Madanur MA, et al. Pseudoaneurysm following laparoscopic cholecystectomy. Hepatobiliary Pancreat Dis Int. 2007;6(3):294-8.

16. Horton KM, Smith C, Fishman EK. MDCT and 3D CT angiography of splanchnic artery aneurysms. AJR Am J Roentgenol. 2007;189(3):641-7

17. Petrou A, et al. Hemobilia due to cystic artery stump pseudoaneurysm following laparoscopic cholecystectomy: case presentation and literature review. Int Surg. 2012;97(2):140-4.

18. Genyk YS, Keller FS, Halpern NB. Hepatic artery pseudoaneurysm and hemobilia following laser laparoscopic cholecystectomy. A case report. Surg Endosc. 1994;8(3):201-4.

19. Yelle J-D, et al. Hemobilia complicating elective laparoscopic cholecystectomy: a case report. Can J Surg. 1996;39(3):240-2.

20. Kwauk STM, et al. Traumatic pseudoaneurysm of the hepatic artery after percutaneous liver biopsy and laparoscopic cholecystectomy in a patient with biliary cirrhosis: a case report. Can J Surg. 1998;41(4):316-20.

21. de Blaauw I, van Driel Repelaer OJ. Hemobilia as a complication of laparoscopic cholecystectomy. Ned Tijdschr Geneeskd. 1999;143(47):2380-3.

22. Nicholson T, et al. Hepatic artery angiography and embolization for hemobilia following laparoscopic cholecystectomy. Cardiovasc Intervent Radiol. 1999;22(1):20-4

23. Dogru O, et al. Hemobilia. Surg Endosc. 2003:17(9):1495-6.

24. lannelli A, et al. Hemobilia due to pseudoaneurysm of the right hepatic artery following laparoscopic cholecystectomy. Gastroenterol Clin Biol. 2003; 27(3 Pt 1):341-3.

25. Roche-Nagle G, Maceneaney, Harte P. Pseudo-aneurysm of the hepatic artery after laparoscopic cholecystectomy: a case report. J Minim Access Surg. 2006;2(2):73-5.

26. Nakase $Y$, et al. Hemobilia and cystic artery stump pseudoaneurysm associated with liver abscess after a laparoscopic cholecystectomy: report of a case. Surg Today. 2008;38(6):567-71.

27. Masannat $\mathrm{YA}$, et al. A rare complication of a common operation: hepatic artery pseudo aneurysm following cholecystectomy report of a case. Ir J Med Sci. 2008;177(4):397-8.

28. Srinivasaiah $\mathrm{N}$, et al. Vascular emergencies in cholelithiasis and cholecystectomy: our experience with two cases and literature review. Hepatobiliary Pancreat Dis Int. 2008;7(2):217-20.

29. Yao CA, Arnell TD. Hepatic artery pseudoaneurysm following laparoscopic cholecystectomy. Am J Surg. 2010;199(1):e10-1.

30. Sansonna F, et al. Severe hemobilia from hepatic artery pseudoaneurysm. Case Rep Gastrointest Med. 2011;2011:925142.
31. Liu Z, Yang S, Xi P. An unusual life-threatening hemobilia caused by hepatic pseudoaneurysm following choledochostomy: a case report. Case Rep Clin Med. 2016;5(02):37.

32. Mate $A D$, et al. Lower gastrointestinal bleeding due to hepatic artery pseudoaneurysm following laparoscopic cholecystectomy. J Minim Access Surg. 2013;9(1):31.

33. El Bouhaddouti $\mathrm{H}$, et al. Hemobilia due to an iatrogenic arteriobiliary fistula complicating laparoscopic cholecystectomy: a case report. Open J Gastroenter. 2014;4(06):275.

34. Traiki TAB, Madkhali AA, Hassanain MM. Hemobilia post laparoscopic cholecystectomy. J Surg Case Rep. 2015;2015:2.

35. Tun-Abraham M, Martínez-Ordaz J, Romero-Hernandez T. Hepatic artery pseudoaneurysm: report of two cases. Cir Cir. 2013;82(6):674-9.

36. Abdalla $\mathrm{S}$, et al. Compressive hematoma Due to pseudoaneurysm of the right hepatic artery: a rare cause of obstructive jaundice after single-port cholecystectomy. Surg Laparosc Endosc Percutan Tech. 2015;25(1):e42-4.

37. Hsiao C-Y, et al. Obstructive jaundice as a complication of a right hepatic artery pseudoaneurysm after laparoscopic cholecystectomy. J Minim Access Surg. 2015;11(2):163.

\section{Submit your next manuscript to BioMed Central and we will help you at every step:}

- We accept pre-submission inquiries

- Our selector tool helps you to find the most relevant journal

- We provide round the clock customer support

- Convenient online submission

- Thorough peer review

- Inclusion in PubMed and all major indexing services

- Maximum visibility for your research

Submit your manuscript at www.biomedcentral.com/submit
Biomed Central 